\title{
Maurizio Ferraris, ¿Dónde estás? Ontología del teléfono móvil, Barcelona: Marbot, 2007, 314 págs.
}

El libro ¿Dónde estás? Ontología del teléfono móvil, del filósofo Maurizio Ferraris (Turín, 1956), se publicó por primera vez en 2005, en italiano, por la editorial Tascabili Bompiani. Su edición en español apareció dos años después en Marbot Ediciones, traducido por Carmen Revilla Guzmán. El Dr. Maurizio Ferraris es profesor de filosofía de la Universidad de Turín y Director del Laboratorio de Ontología-Turín. Pensador formado dentro del posmodernismo filosófico europeo: seguidor de Hans-Georg Gadamer, colega de Jacques Derrida y alumno directo de Gianni Vattimo, se distancia del esquema de pensamiento en la década de los noventa del siglo pasado. La transgresión epistémica ocurre cuando pasa de la Hermenéutica a la Ontología, pues una hermenéutica sin ontología es como ir de viaje en el desierto sin un mapa. La interpretación del discurso y deconstrucción del texto y el lenguaje le resultaban menos fundamentales que el objeto en sí mismo y la objetividad de las cosas. Junto con un grupo de filósofos -dentro de los que destacan Markus Gabriel, Quentin Meillassoux, Graham Harman, Mauricio H. Beuchot, José Luis Jerez-, Ferraris retoma el (Nuevo) Realismo filosófico de inicios del siglo $\mathrm{XX}^{\mathrm{I}}$ sin pugnar por una vuelta a la modernidad, instaura la "realidad" como prioridad y da un giro en el paradigma de la filosofía contemporánea. Rompe con el mito nietzscheano de que "no hay he-

* Magíster en Humanidades. Universidad Autónoma de Guerrero, México. E-Mail: hayledmartin85@hotmail.com

I El New Realism fue un movimiento post-idealista de inicios del siglo XX que se expuso como contrapartida al dualismo epistemológico lockeano, conformado por un grupo de profesores norteamericanos de las universidades de Harvard, Rutgers, Columbia y Princeton: Edwin B. Holt, Walter T. Marvin, William P. Montague, Ralph B. Perry, Walter B. Pitkin y Edward G. Spaulding (Holt, E.B. et al. (20I2). The new realism. Cooperative studies in philosophy. New York: Macmillan). Este movimiento filosófico pasó sin grandes sobresaltos en el mundo de la filosofía. Se retoma ahora en gran medida por el aldabonazo filosófico de Ferraris y compañía. 
chos, solo interpretaciones". Surge así el Nuevo Realismo. ${ }^{2} \mathrm{Al}$ decir de Ferraris, "la elaboración del realismo ha sido, en efecto, el hilo conductor de mi trabajo filosófico después del viraje que, a inicios de los años 90 del siglo pasado, me llevó a abandonar la hermenéutica para proponer una estética como teoría de la sensibilidad, una ontología natural como teoría de la inenmendabilidad y, finalmente, una ontología social como teoría de la documentalidad" (Ferraris 20I2, xi).

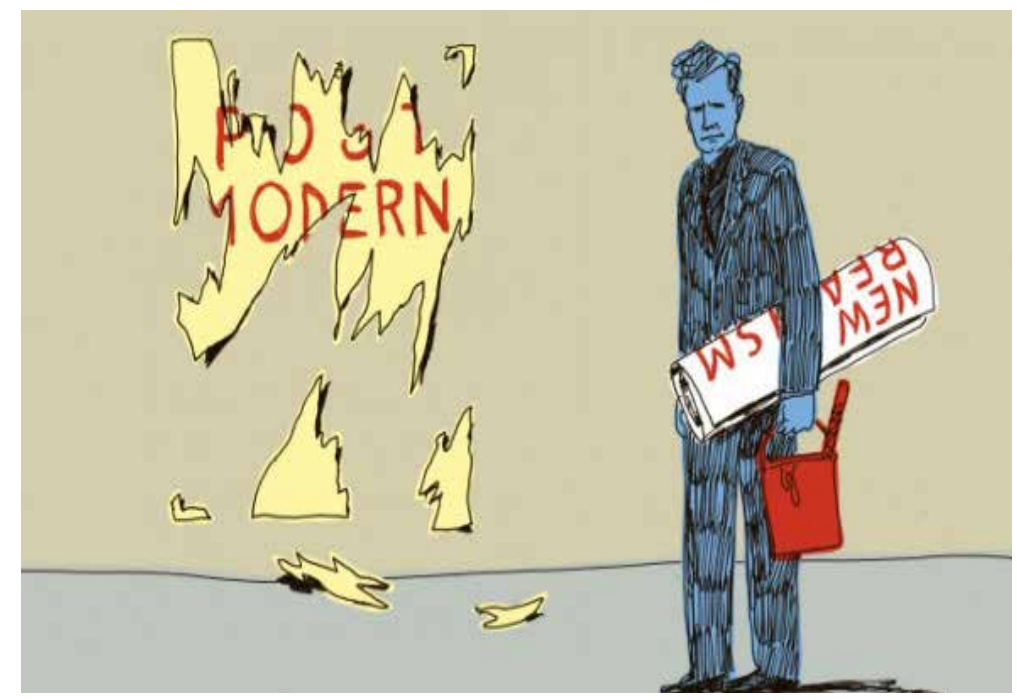

¿Dónde estás? Ontología del teléfono móvil es sin duda una obra cardinal en el campo de la filosofía contemporánea. Adquiere mucha más pertinencia, cuando el contexto tecnológico que vive el mundo hoy es mucho más complejo: esta vez el objeto es el celular. Por supuesto, no se trata de declarar urbi et orbis y vociferar el descubrimiento. Se trata de la aplicación de este tipo de tecnologías y las transformaciones que originan en el ser humano y sus relaciones sociales. La inscripción, -iscrizioni-marcature, pasa a jugar un papel fundamental. El nuevo realismo de Ferraris no trata de limitarse a afirmar la existencia de objetos exteriores, acentuando que lo real no depende del pensamiento: lo real sin humanos no sería pensado.

El ensayo filosófico está estructurado en dos capítulos. Comienza con una especie de prólogo que hace Umberto Eco, titulado "El teléfono

2 Véase Ferraris, M. (20I2). Manifesto del nuovo realismo. Bari: Gius. Laterza \& Figli. 
móvil y la verdad"; después le sigue una nota introductoria del autor “¿Dónde estás?”. El primer capítulo se titula "Perì mail”, y el segundo "Objetos sociales", intercalados por el escrito "El genio en la botella". Cierra el libro con el Epílogo.

Nada existe fuera del texto, dice Derrida, pero a menudo esta frase ha sido tergiversada. "Fuera del texto existe todo un mundo, pero sin inscripciones no existe el mundo social". Ésta es la tesis fundamental: la ontología social se apoya en un sistema de escritura del que el móvil constituye la realidad absoluta, "puesto que permite o promete la conexión a todos los sistemas de comunicación oral y escrita, el acceso a todos los circuitos de registro (escritura, imágenes, música)" (Ferraris 2008, pp. 26-27).

Texto provocador que con sólo comenzar su lectura ocupa al lector en la cuestión fundamental de la différance entre el teléfono fijo y el teléfono móvil. Utiliza el recurso ontológico en ambos casos para preguntar, en el primer caso, “¿quién habla?" o “¿quién es?”; y en el segundo caso, “¿dónde estás?". Si en el primer caso se preguntaba por la existencia de alguien en un lugar determinado, en el segundo caso, se sabe quien responde y solo se pregunta por su ubicación. El primero busca disponibilidad; el segundo siempre está disponible, salva excepciones voluntarias (como apagar el móvil). El objetivo filosófico del texto es el cambio de paradigmas del ser humano con respecto al teléfono móvil, pues éste pasa de ser un simple objeto para hablar (comunicación) para convertirse cada vez más en un medio de almacenamiento (escritura, lectura, registro, datos...). Transforma al ser en homo cellularis. El ambiente es creado desde el teléfono móvil, y no solo centra su atención en la relación del sujeto con el objeto, sino también en la metafísica que se crea con el uso del móvil. Desarrolla un par de tesis con respecto al teléfono móvil: "lo que hay" (ontología) y "lo que el ser humano conoce que hay" (gnoseología) - que al final el objeto no aliena a la persona sino que muestra su desconocimiento frente a la cosa y su incapacidad para asimilarlo en el estado cosas existentes. El teléfono móvil cambia las relaciones entre personas; así por ejemplo, un mensaje de Whatsapp es una nueva forma de relaciones sociales, y ni que hablar de las Redes Sociales como Facebook, Instagram, Twitter, etc., que complejizan aun más este tipo de relaciones. A todo esto hay que agregar que son relaciones sociales que no llevan en sí valor, capital, dinero... y si se ve desde una de las categorías principales para generar riqueza, el trabajo, se puede afirmar que millones de personas en el mundo trabajan sin ser pagados y además pagan por trabajar. Cuando se navega se producen datos y por lo tanto se produce valor, que este a su vez genera un plusvalor. 
"El genio de la botella" de Stevenson, y su relación con la filosofía actual: en verdad no se ha elaborado sistema filosófico nuevo, solo se dividen aquellas otrora filosofías de antaño hasta llegar a nuestros días sin pensamiento que fragmentar. En este sentido, Ferraris hace referencia a la "muerte de la filosofia" en el siglo XIX con los últimos reductos de verdadera filosofía: iluminismo francés, idealismo alemán, marxismo; y la última explosión en los saberes con la irrupción del psicoanálisis freudiano a finales de aquel siglo y principios del XX. Para este apartado stevensoniano utiliza el intertexto y al final terminar increpando a Nietzsche, Heidegger, Rorty y hasta su amigo Derrida.

Ferraris toma como pretexto el celular para ilustrar al lector con esta nueva filosofía o modo de filosofar, y dar un sistema filosófico completo, donde resalta su ontología; pero es completo en el sentido que también se encuentra una epistemología, una gnoseología, una ética, una estética, incluso una hermenéutica cuando deconstruye la realidad existente en el campo de la filosofía conocido como posmodernismo.

¿Y su filosofía? Su filosofía invita a la máxima kantiana sapere aude de atreverte a saber, y pregunta sobre el propio sentido de la filosofía ¿qué es la filosofía? y ¿qué función tiene la filosofía?, y en esto todos estamos de acuerdo, su función fundamental es la de liberar y emancipar a los seres humanos. Igual que Rousseau, Hegel o Marx, busca el Principio de Totalidad, y respeta las diferencias. Si la totalidad es inmanente; la filosofía es inmanente. Tal vez la conclusión final del libro sea la expuesta por Umberto Eco al comienzo del texto cuando señala, "el aspecto más interesante del libro no es que el móvil le haya permitido a Ferraris desarrollar una ontología, sino que su ontología le haya permitido entender y hacernos entender el teléfono móvil".

\section{Referencias bibliográficas}

Ferraris, M. (2007). ¿Dónde estás? Ontología del teléfono móvil (trad. Carmen Revilla Guzmán). Barcelona: Marbot Ediciones. (2012). Manifiesto del nuevo realismo (trad. José Blanco Jiménez). Santiago de Chile: Ariadna Ediciones 